\title{
Room-temperature Suzuki-Miyaura reactions mediated by native and derivatized $\beta$-cyclodextrins
}

\author{
Aires da Conceição Silva ${ }^{1}$, Jaqueline D. Senra ${ }^{2^{\star}}$, Lúcia C. S. Aguiar ${ }^{1,2}$, Alessandro B. \\ C. Simas ${ }^{2}$, Andréa Luzia F. de Souza ${ }^{1}$, Luiz Fernando B. Malta ${ }^{1}$ \\ ${ }^{1}$ Instituto de Química, Universidade Federal do Rio de Janeiro, CT Bloco A Labs. 641 e 617, RJ, Brazil \\ ${ }^{2}$ Núcleo de Pesquisas de Produtos Naturais, Universidade Federal do Rio de Janeiro, RJ, Brazil \\ *e-mail: jdsenra@hotmail.com
}

Keywords: Cyclodextrins, Palladium, Suzuki reactions

\section{INTRODUCTION}

Suzuki-Miyaura reactions provide a simple and effective synthetic route to biaryls by using a wide range of palladium catalysts ${ }^{1,2}$. Our group has recently showed that 2-hydroxypropyl-a-cyclodextrin is an effective green reductant/capping agent for the preparation of $\mathrm{Pd}$ nanoparticles ${ }^{3}$ with good catalytic activity in C-C cross-couplings in water. In this work, we present our findings concerning the effect of different $\beta$-CDs on the room-temperature SuzukiMiyaura reaction between phenylboronic acid and 4bromoacetophenone in the isopropyl alcohol-water system. The results suggest that the nature of the substituents and CD concentration play a role in the catalysis.

\section{RESULTS AND DISCUSSION}

As expected, the attempt to render the model reaction (Scheme 1) selective in neat water at roomtemperature (in the absence of native $\beta-C D$ ) led to a low yield of 4-phenylacetophenone by using $\mathrm{Na}_{2} \mathrm{PdCl}_{4}$ (1 mol\%, entry 1$)$. Through a tentative choice, the addition of $10 \%$ isopropyl alcohol provided only a moderate yield of the product (entry 2). Following this, we carried out a screening using different $\beta$-CD concentrations. Entries 5 and 6 gave the best results, even though biphenyl was observed as by-product $(<15 \%)$. Interestingly, by applying 2 hydroxypropyl- $\beta-C D$ ( $\beta-H P C D$, entry 7$)$ provided the desired product with total product selectivity. Surprisingly, the use of RAME- $\beta-C D$ (randomly methylated), a well-reported mass-transfer/capping agent, resulted only in a moderate yield (entry 8).
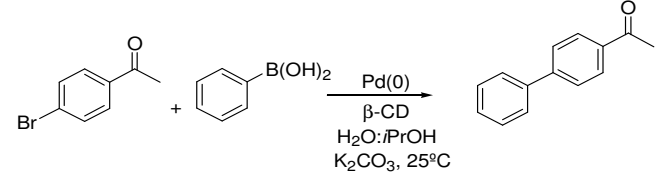

Scheme 1. The Suzuki-Miyaura reaction model.

These previous results suggest that the type of CD along with the $\mathrm{Pd}: C D$ molar ratio has a decisive influence on the yield/selectivity of the reaction, probably as a consequence of the nanoparticle formation. The synthetic scope involving different aryl bromides/boronic acids are under investigation.

Table 1. Suzuki reaction between 4-bromoacetophenone and phenylboronic acid.

\begin{tabular}{|c|c|c|c|}
\hline Entry & Solvent & $\mathrm{Pd}: \beta C D$ & Yield $^{\mathrm{a}}(\%)$ \\
\hline 1 & $\mathrm{H}_{2} \mathrm{O}$ & - & 24 \\
\hline 2 & $\begin{array}{c}\mathrm{H}_{2} \mathrm{O}: i-\mathrm{PrOH} \\
\text { (90\%:10\%) }\end{array}$ & - & 68 \\
\hline 3 & $\begin{array}{c}\mathrm{H}_{2} \mathrm{O}: i-\mathrm{PrOH} \\
(90 \%: 10 \%)\end{array}$ & $10: 1$ & 57 \\
\hline 4 & $\begin{array}{l}\mathrm{H}_{2} \mathrm{O}: j-\mathrm{PrOH} \\
\text { (90\%:10\%) }\end{array}$ & $2: 1$ & 71 \\
\hline 5 & $\begin{array}{c}\mathrm{H}_{2} \mathrm{O}: j-\mathrm{PrOH} \\
(90 \%: 10 \%)\end{array}$ & $1: 2$ & $86^{\circ}$ \\
\hline 6 & $\begin{array}{l}\mathrm{H}_{2} \mathrm{O}: i-\mathrm{PrOH} \\
\text { (90\%:10\%) }\end{array}$ & $1: 10$ & 82 \\
\hline 7 & $\begin{array}{l}\mathrm{H}_{2} \mathrm{O}: i-\mathrm{PrOH} \\
\text { (90\%:10\%) }\end{array}$ & $1: 10$ & $85^{(c)}$ \\
\hline 8 & $\begin{array}{l}\mathrm{H}_{2} \mathrm{O}: i-\mathrm{PrOH} \\
(90 \%: 10 \%)\end{array}$ & $1: 10$ & $53^{(\mathrm{d}, \mathrm{e})}$ \\
\hline
\end{tabular}

\section{CONCLUSION}

The use of $\beta-C D$ s as supramolecular carriers provides an alternative route to perform SuzukiMiyaura reactions under exceptionally mild conditions (aqueous medium and roomtemperature).

\section{ACKNOWLEDGEMENTS}

CNPq, CAPES, FAPERJ, FUJB, IQ/UFRJ.

\section{REFERENCES}

${ }^{1}$ Miyaura, N.; Suzuki, A. Chem. Rev. 1995, 95, 2457

${ }^{2}$ Bellina, F.; Carpita, A.; Rossi, R. Synthesis 2004, 15, 2419.

${ }^{3}$ Senra, J. D.; Malta, L. F. B.; Costa, M. E. H. M.; Aguiar, L. C. S.; Simas,

A. B. C.; Antunes, O. A. C. Adv. Synth. Catal. 2009, 351, 2411. 